\title{
Análise de vídeos didáticos autorais desenvolvidos no contexto da tecnodocência
}

\section{Analysis of authorial didactic videos developed in the context of technoteaching}

\author{
Luciana de Lima ${ }^{1 *}$, Maria Ariane Cardoso da Rocha ${ }^{1}$, Danielle Gonzaga da Silva ${ }^{1}$, Robson \\ Carlos Loureiro ${ }^{1}$
}

\begin{abstract}
RESUMO
O objetivo da pesquisa é descrever as características técnicas e metodológicas dos vídeos produzidos pelos licenciandos que cursaram a disciplina Tecnodocência, ofertada por Instituição Pública de Ensino Superior (IPES). A pesquisa apresenta caráter descritivo com abordagem qualitativa. A unidade de análise é composta por três vídeos desenvolvidos por grupos interdisciplinares. Como instrumento de coleta de dados é utilizada planilha eletrônica e relatório, para transcrição das informações e para mapeamento descritivo de cada vídeo. A análise de dados pauta-se na descrição e na interpretação dos dados por meio da comparação direta com o referencial teórico, destacando-se duas categorias: elementos técnicos e elementos metodológicos. Os vídeos didáticos se caracterizaram como vídeos de mediação, voltados principalmente para aulas expositivas. As obras analisadas demonstraram preocupação maior quanto aos atributos metodológicos, buscando trabalhar os conteúdos de maneira interdisciplinar. As características técnicas se mantiveram em níveis possíveis de reprodução em sala de aula.
\end{abstract}

Palavras-chave: Audiovisual; Autoria; Docência; Tecnologia Digital.

\begin{abstract}
The research objective is to describe the technical and methodological characteristics of the videos produced by the undergraduates who attended the Technoteaching course offered by a Public Institution of Higher Education (PIHE). The research has a descriptive character with a qualitative approach. The unit of analysis consists of three videos developed by interdisciplinary groups. As an instrument for data collection, an electronic spreadsheet and report are used to transcribe each video's information and descriptive mapping. Data analysis is based on the description and interpretation of data through direct comparison with the theoretical framework, highlighting two categories: technical elements and methodological elements. The educational videos were characterized as mediation videos, aimed mainly at expository classes. On the other hand, the analyzed works showed more significant concern with the methodological attributes, seeking to work the contents interdisciplinary. Nevertheless, the technical characteristics remained at possible reproduction levels in the classroom.
\end{abstract}

Keywords: Audiovisual; Authorship; Teaching; Digital Technology.

\footnotetext{
${ }^{1}$ Universidade Federal do Ceará.

*E-mail: luciana@virtual.ufc.br
} 


\section{INTRODUÇÃO}

Como princípio dos Parâmetros Curriculares Nacionais (BRASIL, 1998), a organização curricular deve firmar a sua base no que cada área do saber pode contribuir para a formação dos estudantes aptos a integrar seus conhecimentos a fim de solucionar problemas do cotidiano e perceber o mundo social. Ou seja, a ideia inicial no processo de aprendizagem é a de estabelecer uma conexão que una o que se aprende ao que se pratica fora da escola.

Para Bahia (2015), a produção de recursos de atua principalmente com o objetivo de potencializar o processo de ensino e de aprendizagem, fazendo-se essencial a apresentação da qualidade necessária para permitir a interação entre professor e estudante. Para ser efetivo, tanto os aspectos tecnológicos quanto metodológicos devem ser avaliados na produção. Foram formuladas bases que indicam características que descrevem vídeos de boa qualidade, e aspectos como "sensibilizar o aluno" e "usar tomadas curtas", contribuindo com indicações para o professor-produtor (BAHIA, 2015).

Os problemas na construção de vídeos didáticos residem no fato de se caracterizar como um dos elementos desafiantes para os docentes, sendo iniciado antes mesmo das gravações. Essa formação ainda ocorre de maneira muito reduzida quando comparada às necessidades das escolas, onde muitos profissionais ainda demonstram resistência ao uso e à incorporação das tecnologias em suas aulas, deixando estático o avanço das práticas pedagógicas (COSTA, 2015).

Para Silva, Prates e Ribeiro (2016), o processo de ensino e de aprendizagem precisa ser contextualizado com o atual momento tecnológico. Durante a formação dos licenciandos, a aproximação com as ferramentas e métodos integrados às tecnologias digitais deve garantir que as futuras aulas acompanhem a evolução tecnológica da sociedade. Pensando nisso, algumas Universidades incluem em suas matrizes curriculares disciplinas que envolvam o estudo das metodologias e aparatos tecnológicos, a fim de complementar a formação de seus professores.

A criação da disciplina Tecnodocência, incluída na matriz curricular da Universidade Federal do Ceará (UFC), a partir de 2015, apresenta como objetivo integrar os conteúdos teóricos às atividades práticas da docência com o desenvolvimento de planejamentos e Materiais Autorais Digitais Educacionais (MADEs) fazendo uso das Tecnologias da Informação e Comunicação (TICs). É uma disciplina optativa, ofertada semestralmente, com 64 horas/aula, contando com encontros presenciais em laboratório informatizado, sendo seus recursos subsidiados pelo Governo Federal mediante o desenvolvimento do Projeto Laboratório Interdisciplinar de Formação de Educadores (LIFE/UFC).

Com a produção dos MADEs na disciplina, os estudantes tiveram a oportunidade de aprender a desenvolver vídeos em diferentes formatos com diferentes recursos metodológicos. Foi trabalhada a integração dos saberes tecnológicos, pedagógicos e específicos de suas áreas do conhecimento, a fim de colaborar para a sua formação. Diante disso, pergunta-se: quais são as 
características técnicas e metodológicas dos vídeos desenvolvidos pelos licenciandos que cursaram a disciplina Tecnodocência?

O objetivo da pesquisa é descrever as características técnicas e metodológicas dos vídeos produzidos pelos licenciandos que cursaram a disciplina Tecnodocência no período de 2018 e 2019. Utiliza-se, para este fim, a metodologia descritiva, onde foram realizadas análises de 3 vídeos escolhidos entre os grupos de estudantes matriculados na disciplina durante esse período. Foram realizadas descrições individuais de cada vídeo, abordando os aspectos que técnicos e didático-metodológicos que envolviam as produções, assim como uma análise comparativa dos três materiais abordados.

\section{A EDUCAÇÃO NO CONTEXTO DIGITAL}

Com o advento da era digital, a sociedade passou por mudanças em sua forma de enxergar e de se comunicar com o mundo. A educação, espaço que antes era tomado apenas pelas antigas metodologias, poderia ter a oportunidade de se transformar a partir das tecnologias atuais. As TICs se tornaram cada vez mais produzidas e utilizadas em âmbito escolar como meio didático (VARGAS; ROCHA; FREIRE, 2007). A popularização dos recursos tecnológicos em sala de aula alterou a forma como o conhecimento é trabalhado, modificando as direções que os saberes percorrem nas relações de professores e alunos. (KLEMENC-KETIS; KERSNIK, 2011),

Diferente da abordagem oral comum, a linguagem de materiais audivisuais tem uma natureza sintética, onde se articulam imagens, sons, falas e poucos textos. E, ao se compreender que o cérebro tem uma capacidade processual 60 mil vezes maior para imagens em relação a textos (CARDOSO, 2013), existe maior eficiência em utilizar o método audiovisual para se compreender o que é explorado em uma aula de forma expositiva. E, mesmo com esse fato, a linguagem audiovisual ainda não é o mais utilizado na cultura acadêmica científica (CARDOSO, 2013). A realidade é outra, mas o docente ainda permanece apegado às antigas metodologias dentro da sala de aula, sendo que esse contraste acaba por atrasar e dificultar a evolução didática nas escolas (SILVA; PRATES; RIBEIRO, 2016).

\section{PRODUÇÃO DE VÍDEOS E FORMAÇÃO DOCENTE}

Para Bahia (2015), se faz necessário a produção de materiais de boa qualidade técnica, onde as metas sejam estabelecidas com antecedência, com planejamento efetivo. O fluxo de elaboração de vídeo é um sistema complexo, formado por diferentes ações, organizadas em cinco fases distintas, onde planejamento, pré-produção, produção, edição e publicação precisam ser minuciosamente compreendidos e trabalhados para que a obra componha uma qualidade técnica mínima necessária (BAHIA; SILVA, 2017). 
Papert (2008) defende a ideia da construção do conhecimento, baseada na realização de uma ação concreta do aprendiz que resulta em um produto palpável, desenvolvido com o auxílio do computador, que seja de interesse de quem o produz. O conhecimento é trabalhado pela sua construção direta pelo estudante, o que torna o professor não mais o agente transmissor do saber, mas o coloca em posição de mediador, de forma que o aluno, finalmente, situe-se como objeto central da aula.

Aliados a esta ideia e pautados no estudo teórico-prático da Teoria da Aprendizagem Significativa de Ausubel (AUSUBEL; NOVAK; HANESIAN, 1980), da Teoria de Fluxo de Czikszentmihalyi (1990), da Filosofia da Diferença com enfoque em Foucault (1979), dos conceitos de Interdisciplinaridade ressaltados por Japiassu (1976), a Universidade Federal do Ceará adicionou a sua grade educacional a disciplina Tecnodocência. Nela, a valorização e a utilização dos conhecimentos prévios dos participantes acontecem por meio da construção do engajamento e do significado do conceito de docência e do desenvolvimento do pensamento crítico-reflexivo sobre a ação da prática docente (LIMA; LOUREIRO, 2019). Os discentes dessa disciplina também abordam a utilização de trabalhos cooperativos, onde são estimulados trabalhos em grupo de forma interdisciplinar. Nesse contexto, é trabalhado o conceito de MADE:

todo e qualquer material educacional desenvolvido por um aprendiz utilizando um equipamento digital conectado ou não à internet com criação, planejamento, execução, reflexão e avaliação desenvolvidos pelo próprio aprendiz individualmente ou em grupo como processo ou produto de ensino, aprendizagem e avaliação. Dessa forma, o desenvolvimento de MADEs estão vinculados à utilização de recursos disponíveis na internet bem como os recursos disponíveis em softwares residentes em computadores utilizados offline para que o professor possa construir de materiais educacionais de forma interdisciplinar com outros professores ou com os alunos a fim de que solucionem desafios que lhe são apresentados de forma contextualizada (LIMA; LOUREIRO, 2019, p. 630).

Por meio dessa variedade de MADEs, os estudantes têm a oportunidade de produzir, durante a disciplina, materiais didáticos em formato de vídeo, onde cada integrante do grupo expõe e trabalha os conteúdos de seus respectivos cursos. Os alunos se tornam responsáveis pelos recursos tecnológicos e referenciais metodológicos que constarão no seu material, seguindo critérios avaliados e escolhidos pelos próprios alunos. Os processos de elaboração do material audiovisual são planejados e executados em grupo, fazendo uma interação entre as disciplinas, de forma a trabalhar seus conteúdos de maneira interdisciplinar.

A produção dos MADEs pode contribuir com os processos de ensino e de aprendizagem, a partir da oportunidade de modificar as iniciativas pedagógicas em sala, como apontados no estudo de Serres e Basso (2009), ao demonstrarem trabalhos utilizando diários virtuais, desenvolvidos pelos próprios estudantes da disciplina de Matemática. Ao permitir essa possibilidade de trabalho com ferramentas digitais aliados aos métodos utilizados no 
Construcionismo, os estudantes podem construir saberes tecnológicos, pedagógicos e específicos de suas áreas do conhecimento, a fim de colaborar para a sua formação antes da entrada oficial para o mercado de trabalho.

\section{METODOLOGIA}

A pesquisa apresenta caráter descritivo com a finalidade de demonstrar os fatos e fenômenos da realidade investigada, sendo uma pesquisa de abordagem qualitativa. $\mathrm{O}$ uso dos métodos qualitativos busca explicar o porquê das coisas, exprimindo o que convém ser feito, porém, não quantificam os valores e as trocas simbólicas nem se submetem à prova de fatos, pois os dados analisados são não-métricos (suscitados e de interação) e se valem de diferentes abordagens (SILVEIRA; CÓRDOVA, 2009).

A unidade de análise do estudo é composta por três vídeos produzidos por grupos interdisciplinares compostos por 10 alunos de Licenciatura: Biologia (4), Letras (2), Física (1), Química (1), Geografia (1), Música (1) e 3 alunos do Bacharelado de Sistemas e Mídias Digitais, vinculados à Universidade Federal do Ceará, participantes da disciplina Tecnodocência ofertada entre os anos de 2018 e 2019.

A pesquisa é dividida em três etapas: planejamento, coleta e análise de dados. A primeira fase é concebida a partir da preparação das estratégias a serem seguidas, assim como dos protocolos, recursos e instrumentos digitais utilizados nas etapas subsequentes.

A segunda etapa ocorre a partir da coleta de 12 vídeos produzidos pelos grupos interdisciplinares da disciplina Tecnodocência. Os vídeos estavam disponíveis a partir de links agrupados no site da disciplina, onde são mantidos os MADEs produzidos pelos estudantes. Os grupos interdisciplinares produzem vídeos na condição de professores que preparam materiais a serem utilizados futuramente com alunos da Educação Básica. Dentre os 12 vídeos, 3 foram escolhidos para dar prosseguimento às análises. Essa escolha ocorreu em função da disponibilidade dos vídeos no local de armazenamento e da qualidade do vídeo para o desenvolvimento do processo analítico. Os instrumentos de coleta foram a planilha eletrônica e relatório de dados, tanto para a transcrição das informações como para o mapeamento descritivo de cada vídeo.

Segundo Bauer e Gaskell (2008), a manipulação de recursos visuais durante uma pesquisa de caráter qualitativo deve ser feita de maneira cuidadosa. Os autores se referem às interpretações de obras audiovisuais como aptas a erros de entendimento devido à característica aberta das análises. Mesmo que um vídeo demonstre um aparato descritivo para um tema, as interpretações podem variar de acordo com o telespectador. A fim de tornar as análises realizadas no presente trabalho mais centradas nos objetivos, na terceira etapa do trabalho foi feita uma descrição de cada vídeo considerando-se 2 categorias: elementos técnicos e elementos metodológicos. 
Os aspectos metodológicos foram selecionados para tipificar as formas com que cada grupo interdisciplinar realizou seus procedimentos no material, sendo estudados a linguagem direta ou indireta; as correlações interdisciplinares; a interação com o futuro estudante; e o papel exercido pelo discente e docente durante o vídeo. Essa forma de análise permite conceber padrões entre diferentes obras, mesmo que ainda estejam sob a influência da perspectiva autoral, que pode alterar os significados qualitativos de um trabalho (BAUER; GASKELL, 2008).

Os elementos técnicos foram avaliados inicialmente de forma individual. As informações técnicas de cada vídeo foram coletadas por meio dos seus registros de dados visualizados nos softwares de reprodução. Qualidade do som; resolução da imagem, duração do material e a presença e ausência de legendas foram verificadas em cada um dos três vídeos estudados.

$\mathrm{Na}$ última etapa das análises, as características técnicas e metodológicas dos 3 vídeos foram comparadas entre si a fim de se discutir as convergências e divergências na utilização de metodologias de ensino e de aprendizagem a partir do uso e do desenvolvimento de materiais audiovisuais digitais. Buscou-se interpretar as preferências dos grupos interdisciplinares nas escolhas relacionadas aos pontos destacados anteriormente, como a resolução dos vídeos e a abordagem dos temas. Para se estabelecer uma comparação, procurou-se frisar os atributos que trazem qualidade aos materiais, sendo destacado por Bahia (2015) que a qualidade é medida pela capacidade da obra de promover a aprendizagem, o contínuo processo de construção e reconstrução do conhecimento, ou seja, ultrapassando os limites de apresentar conteúdos.

\section{RESULTADOS E DISCUSSÃO}

Os resultados apresentados nas próximas seções dizem respeito às análises individuais de cada vídeo estudado, por meio da análise de seus atributos metodológicos e técnicos, onde são destacadas as etapas da produção das obras. Na última seção, foi realizada uma análise comparativa entre os materiais, a fim de se atender ao objetivo do trabalho na compreensão da elaboração de conteúdos audiovisuais pelos grupos interdisciplinares. As informações a seguir são apresentadas por meio das interpretações dos vídeos, sendo pautadas no referencial teórico utilizado.

\section{Análise do Vídeo 1}

$\mathrm{O}$ primeiro vídeo ${ }^{2}$ analisado iniciou com a proposta de conectar o espectador à ideia de superpoderes de uma maneira mais real, fazendo uma conexão entre o universo espetacular dos

\footnotetext{
${ }^{2}$ https://drive.google.com/file/d/18OJWizT8aH435CvPFv_ywaoc3p8LPjcN/view
} 
super-heróis e a vida cotidiana. Foram trabalhadas informações que conectam as obras a realidade, como o ganho dos superpoderes a princípios biológicos, como mutação, ou pela experimentação científica.

Na parte final, traçando um elo entre os filmes de cinema e a vida real, o vídeo considerou a presença da personalidade atual do Bill Gates, fundador da empresa de software Microsoft (GUIMARÃES, 2005). A capacidade de produzir ferramentas tecnológicas a fim de facilitar a vida humana também foi apresentada no vídeo, além do exemplo real, pelo próprio cinema, onde personagens como Tony Stark e Bruce Wayne são citados como criadores das mais variadas ferramentas tecnológicas para combater o crime ou ajudar as pessoas de diferentes formas.

Para a construção desse material, os autores utilizaram o gênero de Vídeo de Mediação, que é o resultado da mediação didático-pedagógica de fragmentos de vídeos já existentes (BAHIA, 2015). De forma rápida, o vídeo abordou conteúdos de Química, Física e Biologia, ao tratarem das características extraordinárias dos super-heróis cinematográficos, sendo indicadas possíveis explicações científicas e ligeiros conceitos para os seus superpoderes.

A metodologia do vídeo foi baseada em uma exposição dos aspectos do tema central, onde as vozes dos componentes dos grupos interdisciplinares tomam o papel do professor ao expor os pontos do material audiovisual relacionados aos conteúdos. Sem espaço para a apresentação mais esclarecedora de ideias ou pontos-chave dos assuntos, foram demonstradas pequenas conexões entre os conceitos científicos e o enredo cinematográfico. Sendo um vídeo bastante curto (03:34 min), as explicações não foram apresentadas de forma muito elaborada, tornando o material um modelo mais introdutório do que propriamente elucidativo.

A proposta do vídeo trabalhou os saberes abordados no material da maneira habitual da sala de aula, com a transmissão de conhecimento de professor para aluno. A utilização do computador manteve o papel de informatização dos métodos de ensino tradicionais. Considerando-se os trabalhos realizados por Papert (2008), a proposta do vídeo estaria mais relacionada à ideia de que a aprendizagem tem seu ponto principal na instrução, diante do aperfeiçoamento da transmissão da informação.

Para abordar os conteúdos, os autores desenvolveram no vídeo diálogos explicativos sobre os temas abordados. O material é composto por trechos de obras cinematográficas, onde a narração é realizada pelos próprios integrantes do grupo interdisciplinar a fim de aproximar o aluno do conteúdo e cativar sua atenção. A escolha da produção foi bem simples, onde a maior parte do desenvolvimento foi a inclusão de frases de mediação durante o vídeo, sendo isso parte fundamental para a consistência didática do material desse gênero (BAHIA, 2015). O material também contou com momentos de pequenas interações, relacionadas às falas com perguntas rápidas para o telespectador, o que denotou um caráter participativo durante as cenas, mas que não garante uma participação clara e direta do aluno com o material quando estiver em uso. 
A linguagem do vídeo apresentou características de uma das etapas primordiais na produção de um MADE, o planejamento. Nessa etapa, para a produção de materiais audiovisuais, são requisitados um roteiro que indiquem as fases de transição do vídeo, para garantir que cada etapa ocorra da melhor forma possível. No vídeo analisado, foi possível identificar que os autores promoveram um diálogo na roteirização, apresentando suas falas como uma narrativa construída, sendo uma estratégia pedagógica utilizada para capturar e manter a atenção do aluno (BAHIA, 2015). Com uma taxa de bits de $127 \mathrm{kbps}$, a qualidade técnica do áudio permitiu uma boa compreensão quando avaliado em um ambiente pessoal, onde não era requerido do som um volume muito alto. Todavia, para a utilização do vídeo em uma sala de aula maior, essa taxa poderia apresentar falhas na reprodução, como chiados ou uma baixa na qualidade da compreensão.

Quanto à imagem transmitida no vídeo, a resolução apresentada foi de 1280×720, uma das resoluções mais utilizadas na contemporaneidade, reconhecida como transmissão de alta definição. Para a construção de um vídeo para fins educacionais, deve-se considerar que o estudante procure por uma informação clara, objetiva e agradável, por isso os elementos compositivos do vídeo devem ser pensados no sentido de auxiliar nesse processo (SCHNEIDER; CAETANO; RIBEIRO, 2012). O vídeo analisado retirou os fragmentos de obras cinematográficas, e a sua linguagem não passou dos limites da fala da narração que prosseguiu por todo o material, estando ausente de legendas.

\section{Análise do Vídeo 2}

O segundo vídeo ${ }^{3}$ analisado inicia com uma introdução rápida a respeito dos jogos e a diversidade de características que prendem o público. Com o exemplo do jogo Super Mario World, de 1990, desenvolvido pela Nintendo (SILVA JUNIOR, 2019), o narrador trata dos aspectos que tornam os jogos um dos gêneros de entretenimento mais disseminados no mundo. Diante desse modelo e da apresentação rápida de outros jogos de gêneros diferentes, é debatido sobre a construção desses enredos virtuais. Partindo da ideia de se investigar melhor a história por trás dos jogos, o vídeo leva à sua segunda etapa. É apresentada uma estrutura utilizada como base em obras literárias e cinematográficas, vinculas à trajetória de um personagem em busca de seus objetivos, conhecida como A Jornada do Herói, ou, simplesmente, Monomito, Criado por Campbell em 1990, (SILVA JUNIOR, 2019).

Na terceira etapa do vídeo, é analisada a parte artística dos jogos. Nessa fase, é destacado não apenas a presença da arte na composição dos jogos virtuais, mas, também, a sua importância

\footnotetext{
${ }^{3}$ https://drive.google.com/file/d/1NgBJhKqy4cjWXesiqdMf-Rh75kHMpEkt/view
} 
para completar essa forma de entretenimento. Estimulando o aluno telespectador a reconhecer determinada melodia, o narrador explica que a importância da música e dos efeitos sonoros nos jogos virtuais acrescenta, juntamente aos elementos gráficos, a ideia realística do jogo.

Chegando a sua etapa final, no vídeo, é apresentado uma estrutura convencional dos jogos virtuais. O narrador explica que a experiência dos jogos é montada de maneira a aproximar mais a jogabilidade do indivíduo a sua própria percepção de ação. Isso acontece pela imposição da parte artística do jogo, juntamente a sua capacidade de impor as regras, que define o que vai ser ou não realizado pelo jogador.

Para aproximar essa ideia da realidade, o material trouxe conceitos biológicos para compreender como essa conexão entre o virtual e o real ocorre para as pessoas, por meio de conceitos-chave da Biologia como "sinais" e "áreas tradutoras", para explicar as ideias de estímulo-ação que programam o desempenho do indivíduo nesses jogos. A partir da discussão desses saberes durante o material, o narrador propõe que o aluno analise os jogos a partir dessa nova perspectiva.

O material construído seguiu, assim como o vídeo anterior, a proposta de vídeo do gênero Mediação (BAHIA, 2015). Foram trabalhados conteúdos de Literatura, Biologia e Arte, ao serem debatidos em contexto dos jogos virtuais. Os autores trouxeram exemplos de jogos de maneira a elucidar conceitos que abrangiam essas áreas, mostrando que essa forma de entretenimento ultrapassa as barreiras da própria atividade, contemplando saberes diversos. A metodologia do vídeo seguiu um padrão de exposição, rodeando o tema central (jogos) com os conceitos gerais dos conteúdos científicos trabalhados. As interações durante o vídeo também foram desenvolvidas de maneira mais reduzida, sendo representadas por pequenas indagações ao longo do material, sendo também breve (03:38 min), com a participação do narrador que incorpora novamente a figura do professor.

Os conteúdos analisados trouxeram ideias para transmitir o conhecimento de maneira mais próxima da realidade, utilizando analogias. Os conceitos que foram trabalhados durante a apresentação também foram reforçados pela aplicação em situações práticas, como mostrados em trechos relacionados ao conteúdo de Biologia. A exemplo disso, o narrador utiliza as funções cerebrais para explicar o desencadeamento de ações como "abrir um baú" ou "bater nele" com a ideia de aproximar os saberes ao tema proposto. Assim como o primeiro vídeo analisado, a narrativa foi criada em etapas, introduzindo-se as primeiras ideias de explicação dos jogos por outra perspectiva, para, então, aplicar as situações didáticas práticas a fim de montar os saberes a serem transmitidos.

Quanto aos efeitos de áudio e visual, a qualidade sonora foi satisfatória a nível de compreensão individual, com taxa de bits de $127 \mathrm{kbps}$. Para salas de aula, poderia ser recomendada a utilização de aparelhos que amplificam o som, o que poderia reduzir a qualidade, dificultando a compreensão. A resolução apresentada no vídeo foi de 1280×720, e, novamente, 
não houve a presença de legendas ou títulos que separassem as etapas do material, o que vai de encontro com as recomendações de materiais didáticos a serem produzidos (SCHNEIDER; CAETANO; RIBEIRO, 2012).

\section{Análise do Vídeo 3}

O terceiro vídeo ${ }^{4}$ analisado foi dividido em quatro etapas principais sobre o tema Exercícios Físicos. Iniciando com vídeo de pessoas praticando diferentes atividades físicas, a narradora traz informações sobre os benefícios que essa prática pode proporcionar ao bem-estar do ser humano. Os autores referiram-se às vantagens como de ordem psicológica, cognitiva, biológica e social, salientando que poderiam ser alcançadas pelas diferentes idades.

A segunda etapa do material tratou de abordar as informações que estão por trás do maquinário biológico do corpo humano. Os movimentos realizados, sejam para atividades físicas ou para a ação cotidiana dos seres humanos, foram abordados seguindo uma escala decrescente de conteúdos. Foram mostrados os papéis dos músculos na dinâmica corporal seguindo até as minúsculas alterações moleculares que regem essas práticas. As explicações apresentadas foram exemplificadas com imagens que traziam as partes humanas analisadas, com forma e estrutura.

$\mathrm{Na}$ terceira e mais detalhada etapa do vídeo, os autores trataram do tema de uma maneira mais aprofundada, trazendo explicações sobre o processo anterior, fundamental para que as atividades físicas ocorram: a alimentação. A narradora desta fase do vídeo inicia com imagens de alimentos e suas respectivas denominações, como proteínas e carboidratos. Com a utilização desse material visual, os autores abordaram temas de fisiologia. Para isso, o vídeo constou com esquemas simplificados, onde as fases de transição foram representadas pelas imagens no decorrer do material.

Finalizando o vídeo, a quarta etapa se distanciou das outras pela exposição de aspectos não diretamente relacionados aos processos de exercícios físicos. Nessa fase, os autores abordaram como a tecnologia, cada vez mais presente, torna-se útil para diferentes ações diárias dos seres humanos, fazendo parte das atividades humanas vitais, com o exemplo do conceito de wearables technology (tecnologia que se pode vestir), que traduz os aparatos tecnológicos que podem ser utilizados pelos usuários como peças do seu próprio vestuário. Nesse ponto, a narradora mostrou como a rotina atual limita as condições físicas de uma pessoa, seja pela falta de tempo para práticas saudáveis, ou pelo estresse que impossibilita o acréscimo de atividades no cotidiano. Para os autores, esse uso das tecnologias serviria para dar maior comodidade ao ser humano, sendo esse um retrato da evolução da computação para a vida das pessoas.

\footnotetext{
${ }^{4}$ https://drive.google.com/file/d/17OH--98wN1R88aUmq5btRvn2ChWV_Dc0/view
} 
Utilizando o Vídeo de Mediação, e com um tempo maior do que os outros vídeos analisados (06:06 min), os autores abordaram os conteúdos das áreas da Biologia, Química e Engenharia da Computação, relacionando-os com o tema Exercícios Físicos. Os autores desenvolveram explicações mais detalhadas abordando os conteúdos a partir de imagens ou de trechos de vídeos relacionados à atividade física. Não houve interações diretas com os telespectadores por meio de questionamentos ou momentos de reflexão. Quase todo material foi voltado a elucidações de conceitos e processos que estavam relacionados ao tema, trazendo uma carga conteudista superior às outras produções.

A linguagem abordada no material também apresentou as características da elaboração de um MADE, com roteirização. Mesmo que não mantivesse uma conversa direta com os alunos, foi possível identificar a formação das fases de transição, com uma etapa introdutória seguida de seu desenvolvimento. O Grupo 3 abordou maior quantidade de informações do conteúdo durante a sua produção. $\mathrm{O}$ uso de conceitos e ideias foi verificado por toda a obra, assim como a explicação de processos mais detalhados. A exemplo disso, é possível citar a utilização de conceitos abordados em Fisiologia do Exercício, como "fibras musculares" e "bandas", em que não apenas foram alocadas no vídeo, mas aplicadas nas explicações processuais. Mesmo com esses detalhes a mais e contando com um tempo maior, a produção novamente usou os recursos digitais de uma forma expositiva, tornando os narradores como figura central do ensino.

A qualidade do vídeo difere dos anteriores, contando com uma resolução de $640 \times 360$. Essa resolução é uma das mais baixas apresentadas atualmente, indicando apenas 360 linhas de resolução vertical. Sua imagem possui dimensões pequenas, e o seu aumento poderia resultar em uma perda significativa de qualidade, podendo indicar problemas para a transmissão desse material em sala de aula pelo uso de projetores, contando ainda com a dificuldade da falta de legendas.

\section{Análise Comparativa}

Os três materiais analisados apresentaram os conteúdos a serem trabalhados a partir do mesmo gênero audiovisual, denominado de Vídeo de Mediação. Isso denota que, em todos os casos, as necessidades demonstradas durante a produção eram, sobretudo, as de sintetizar conceitos e a de estabelecer relações entre o tema estudado e o desenrolar do vídeo.

Iniciando com os aspectos tecnológicos, as produções audiovisuais contaram com mais semelhanças do que diferenças quando se tratava da qualidade de som e imagem. Os vídeos e imagens escolhidos se caracterizaram por desenhos bem definidos e cores vibrantes, podendo despertar a atenção do telespectador, assim como elucidativos quando tratavam de abordar conceitos como os de músculo (Grupo 3) ou abordar a cíclica Jornada do Herói (Grupo 2). 
A utilização de efeitos visuais foi bastante empregada nos materiais, todavia, a qualidade deixou alguns pontos a serem revistos pelos autores. Para os grupos 1 e 2, foram identificados maiores erros no desenvolvimento dos conteúdos, ou seja, na metodologia que foi empregada na produção. No terceiro vídeo, as áreas abordadas tiveram maior espaço para tratar de seus conteúdos, e os conhecimentos foram desenvolvidos com maior riqueza de detalhes. Entretanto, em comparação aos outros dois primeiros grupos analisados, o Grupo 3 foi pouco eficiente nos aspectos técnicos, com a qualidade de som e imagens abaixo do esperado para materiais didáticos.

Nos grupos 2 e 3, a produção se caracterizou, em determinados momentos, pela transposição para o vídeo da aula expositiva comum. As imagens estáticas acompanhadas por longas explicações deixaram, muitas vezes, espaços para que os estudantes pudessem perder o interesse no assunto, o que faz com que conceitos e explicações importantes da aula se perdessem por um desvio - mesmo rápido - da atenção. É importante frisar que isso não indica que a utilização de imagens seja uma ideia totalmente excluída, mas que seja alocada de maneira a mediar o conhecimento, e não se tornar uma peça única que o contenha.

Em se tratando dos trechos dos vídeos abordados pelo grupo 1, é possível identificar outro problema, evitado pelas outras equipes. Mesmo que os grupos 2 e 3 tenham deixado momentos de explicações mais longas com imagens estáticas, as duas produções conseguiram conectar as narrativas com o material audiovisual quase integralmente, não interligando apenas o tema, mas os conteúdos científicos apresentados nos vídeos. O material do grupo 1 trouxe apenas os trechos de obras já produzidas e a sua mediação ocorreu totalmente de forma verbal. Isso poderia ser um problema, pois em momentos em que os produtores abordaram rapidamente os conceitos que queriam trabalhar, a atenção poderia estar voltada apenas ao conteúdo visual mostrado, que não demonstrava uma conexão direta com a explicação teórica científica dos fatos.

Em relação aos atributos técnicos, as análises realizadas nos materiais audiovisuais demonstraram uma pequena dificuldade em relação à qualidade de som e imagem. As três produções avaliadas não ultrapassaram a qualidade de resolução de 1280×720 (Grupos 1 e 2), o que poderia interferir na visualização caso houvesse uma transmissão dentro de sala de aula. $\mathrm{O}$ grupo 3 apresentou a resolução $640 \times 360$, com um nível ainda inferior de qualidade.

Os atributos sonoros não afetaram diretamente o entendimento nos vídeos, mas é importante ressaltar que a análise foi realizada de forma individual, com equipamento que supriu apenas a necessidade de uma pessoa. Isso indica que, para transmissões maiores (em salas de aula ou auditório), é preciso ter mais atenção na qualidade sonora, pois a utilização de amplificadores de som pode alterar a qualidade das taxas de bits.

No que diz respeito aos aspectos metodológicos, a principal semelhança entre os três grupos foi a organização das etapas de cada produção. A roteirização aconteceu de forma a construir uma espécie de narrativa de aprendizagem, onde os narradores fizeram um caminho moldado pelos conteúdos adicionados no material. Todos abordaram inicialmente o tema com 
uma conversa rápida, introduzindo a ideia a fim de chamar a atenção e cativar a curiosidade do aluno telespectador. Os conteúdos de cada área foram conectados através do tema e isso facilitou a ideia do saber interdisciplinar.

A apresentação dos conteúdos manteve uma pequena variação entre os três grupos estudados. Todos sustentaram uma forte conexão à elucidação de conceitos, seja para utilizar apenas a sua definição (Grupo 1 e 2) ou para aplicar a uma explicação mais ampla (Grupo 3). Para tentar fortalecer a conexão com os saberes que estavam sendo trabalhados, os três grupos também atuaram na ideia de aplicar situações práticas aos temas abordados. Apresentando exemplos reais ou instigando os estudantes a pensarem sobre o que estava sendo mostrado, os autores tentaram aproximar o conteúdo a uma compreensão mais presente no cotidiano dos estudantes, revelando tentativas de se montar uma aprendizagem mais significativa com o uso dos vídeos didáticos.

Mesmo sendo uma alternativa viável para as aulas expositivas tradicionais, os vídeos didáticos muitas vezes carregam ainda características de uma aula expositiva como aquela aplicada em sala de aula. No caso dos materiais analisados, a presença do professor, caracterizada como narrador, foi atribuída como figura central, de onde se parte o conhecimento. Esse aspecto acarreta na configuração do estudante como figura passiva no processo de aprendizagem, o que pode tornar o ensino menos efetivo por privar o aluno das descobertas realizadas quando este mesmo atua no papel principal para a construção do saber (PAPERT, 2008).

\section{CONSIDERAÇÕES FINAIS}

A construção de materiais por parte dos professores tem sua importância dirigida não apenas aos aparatos que são utilizados para essa finalidade, mas também na busca de uma necessária qualidade que permita a interação entre professor e estudante. Para isso ocorrer de maneira efetiva, tanto os aspectos tecnológicos quanto metodológicos devem ser avaliados cuidadosamente na produção desses materiais.

Considerando-se que o objetivo da pesquisa foi descrever as características técnicas e metodológicas dos vídeos produzidos pelos licenciandos que cursaram a disciplina Tecnodocência no período de 2018 e 2019 em Instituição Pública de Ensino Superior, as análises dos vídeos produzidos traçaram uma linha de semelhanças apresentadas durante a execução, tanto na parte técnica, quanto nos atributos metodológicos. Foi possível identificar que os autores buscaram alcançar a interação entre os principais atores dos processos de ensino e de aprendizagem: professor e estudante, por meio dos recursos de audiovisual, utilizando-se de uma exposição do que é falado. A narração integral e as imagens de apoio apresentaram um caráter expositivo, assim como o trabalho evidente com a interdisciplinaridade.

A construção dos vídeos pelos autores demonstrou ainda evidências do excesso de conteúdo repassado pelos autores no papel de professores. Mesmo em um vídeo curto, reforçaram 
o método conceitual, onde um maior número de descrições foi narrado durante a apresentação. Mesmo com o enfoque semelhante a uma aula expositiva comum, o acréscimo do vídeo permitiu aos autores a possibilidade de cativar a atenção dos estudantes. Demonstrou que esse material pode ter desempenho satisfatório com a finalidade de aproximar a comunicação entre docente e discente.

A descrição das características técnicas e metodológicas dos vídeos produzidos demonstrou uma preferência dos autores por manter uma base padronizada de transmissão e recepção do conteúdo. Utilizando a interdisciplinaridade entre as diferentes áreas do saber envolvidas, os autores buscaram explorar os temas aplicando o máximo de conceitos e descrições por meio do desenvolvimento de vídeos de mediação.

Com a prevalência de uma proposta docente pautada na transmissão do conhecimento, os autores também se preocuparam com a integração da tecnologia ao processo de gravação de vídeo e com o trabalho interdisciplinar, conectando os saberes envolvidos e mostrando possibilidades mais holísticas de compreendê-los. As propostas de audiovisual desenvolvidas apresentaram uma preocupação de chamar mais a atenção dos alunos, mas também de levar ao exercício do pensamento criativo.

A pesquisa, no entanto, apresentou limitações, uma vez que investigou um grupo seleto de produções de alunos em condições especiais de ensino e de aprendizagem. Esse aspecto impossibilitou generalizações do fenômeno. Diante dessa perspectiva, tem-se como perspectiva futura a continuidade da pesquisa com estudantes do Ensino Superior de diferentes Universidades, em diferentes contextos, uma vez que desenvolvam materiais audiovisuais para docência.

\section{REFERÊNCIAS}

AUSUBEL, D. P; NOVAK, J. D.; HANESIAN, H. Psicologia Educacional. Rio de Janeiro: Interamericana, 1980.

BAHIA, A. B.; SILVA, A. R. L D. Modelo de produção de vídeo didático para EaD. Revista Paidéi@-Revista Científica de Educação a Distância, v. 9, n. 16, p. 1-15, 2017.

BAHIA, A. B.; SILVA, A. Regina L. D. Vídeo didático: um guia para o professor. Florianópolis: IFSC, 2015.

BAUER, M. M.; GASKELL, G. Pesquisa Qualitativa com texto, imagem e som: um guia prático. Petrópolis, RJ: Editora Vozes, 2008.

BRASIL. Secretaria de Educação Fundamental. Parâmetros curriculares nacionais $\mathbf{5}^{\mathbf{a}} \mathbf{a} \mathbf{8}^{\mathbf{a}}$ séries. Brasília: MEC/SEF, 1998. Disponível em: <http://portal.mec.gov.br/index. php?view=article\&id=12657>. Acesso em: 20 out. 2020 .

CARDOSO, C. A. O vídeo instrucional como recurso digital em educação a distância. Revista Trilha Digital, v. 1, n. 1, p. 1-15, 2013. 
COSTA, S. M. A influência dos recursos tecnológicos no processo de ensino aprendizagem. 2014. 43f. Trabalho de Conclusão de Curso (Especialização em Fundamentos da Educação: Práticas Pedagógicas Interdisciplinares) - Universidade Estadual da Paraíba, 2015.

CZIKSZENTMIHALYI, M. Flow: the psychology of optimal experience. New York: Harper Perennial, 1990.

FOUCAULT, M. A Microfísica do Poder. Rio de Janeiro: Edições Graal, 1979.

GUIMARÃES, A. T. R. Linux x Microsoft: as novas tendências do mercado de sistemas operacionais. Transformação, v 17, n. 1, p. 79-90, 2005.

JAPIASSU, H. Interdisciplinaridade e patologia do saber. Rio de Janeiro: Imago, 1976.

KLEMENC-KETIS, Z.; KERSNIK, J. Using movies to teach professionalism to medical students. BMC medical education, v. 11, n. 1, p. 1-5, 2011.

LIMA, L. D.; LOUREIRO, R. C. Integração entre Docência e Tecnologia Digital: o desenvolvimento de Materiais Autorais Digitais Educacionais em contexto interdisciplinar. Colóquio Internacional Educação e Contemporaneidade, v. 13, n. 14, p. e13191418e13191418, 2019.

PAPERT, S. A Máquina das Crianças: repensando a escola na era digital. Porto Alegre: Artmed, 2008.

SERRES, F.; BASSO, M. V. de A. Mídias Digitais de Comunicação: autoria e aprendizagem de Matemática. Workshop de Informática na Escola, 15, Bento Gonçalves, RS, 2009.

SCHNEIDER, C. K.; CAETANO, L.; RIBEIRO, L. O. M. Análise de vídeos educacionais no YouTube: caracteres e legibilidade. Revista Novas Tecnologias na Educação, v. 10, n. 1, p. 115, 2012.

SILVA, I. D. C. S.; PRATES, T. D. S.; RIBEIRO, L. F. S. As novas tecnologias e aprendizagem: desafios enfrentados pelo professor na sala de aula. Revista em Debate, n. 15, p. 107-123, 2016.

SILVA JUNIOR, M. S. T. D. Apontamentos sobre a narratividade e a aspectualização do ato de jogar no jogo Super Mario World/Narrativity and aspectualization on playing Super Mario World. Texto Livre: Linguagem e Tecnologia, v. 12, n. 1, p. 85-111, 2019.

SILVEIRA, D. T.; CÓRDOVA, F. P. A pesquisa científica. Métodos de pesquisa, v. 1, p. 31, 2009.

VARGAS, A.; ROCHA, H. V. D.; FREIRE, F. M. P. Promídia: produção de vídeos digitais no contexto educacional. Revista Novas Tecnologias na Educação, v. 5, n. 2, p. 10-25, 2007.

\section{Recebido em: 05/01/2022}

Aprovado em: 08/02/2022

Publicado em: 11/02/2022 